\title{
Pain measurement as part of primary healthcare of adult patients with sickle cell disease
}

\author{
Andreza Aparecida Felix Signorelli ${ }^{1}$ \\ Sonia Beatriz Felix Ribeiro ${ }^{1}$ \\ Helio Moraes-Souza ${ }^{1,2}$ \\ Lucas Felix de Oliveira ${ }^{3}$ \\ João Batista Ribeiro ${ }^{1}$ \\ Sheron Hellen da Silva ${ }^{1}$ \\ Daniel Fachinelli Felix de Oliveira \\ Matheus Fernando Felix Ribeiro ${ }^{4}$
}

${ }^{1}$ Universidade Federal do Triângulo Mineiro

- UFTM, Uberaba, MG, Brazil

${ }^{2}$ Fundação Centro de Hematologia e

Hemoterapia de Minas Gerais - Fundação Hemominas, Belo Horizonte, MG, Brazil

${ }^{3}$ Secretaria Municipal de Saúde de Uberaba, Uberaba, MG, Brazil

${ }^{4}$ Universidade Federal de Minas Gerais,

UFMG, Belo Horizonte, MG, Brazil
Conflict-of-interest disclosure:

The authors declare no competing financial interest

Submitted: 7/22/2012

Accepted: 11/19/2012

Corresponding author:

Andreza Aparecida Felix Signorelli

Universidade Federal do Triângulo Mineiro

Avenida Frei Paulino, 30 Bairro Nossa

Senhora da Abadia

38.025-180 Uberaba, MG, Brazil

andreza.signorelli@gmail.com
Objective: The aim of this exploratory, cross-sectional study was to evaluate pain in sickle cell disease patients and aspects related to primary healthcare.

Methods: Data were obtained through home interviews. The assessment instruments (body diagram, Numerical Pain Scale, McGill Pain Questionnaire) collected information on the underlying disease and on pain. Data were analyzed using the Statistical Package for Social Sciences program for Windows. Associations between the subgroups of sickle cell disease patients (hemoglobin SS, hemoglobin SC, sickle $\beta$-thalassemia and others) and pain were analyzed using contingency tables and non-parametric tests of association (classic chi-square, Fisher's and Kruskal-Wallis) with a level of 5\% (p-value <0.05) being set for the rejection of the null hypothesis .

Results: Forty-seven over 18-year-old patients with sickle cell disease were evaluated. Most were black (78.7\%) and female (59.6\%) and the mean age was 30.1 years. The average number of bouts of pain annually was 7.02 ; pain was predominantly reported by individuals with sickle cell anemia (hemoglobin SS). The intensity of pain (Numeric Pain Scale) was 5.5 and the quantitative index (McGill) was 35.9. This study also shows that patients presented a high frequency of moderately painful crises in their own homes.

Conclusion: According to these facts, it is essential that pain related to sickle cell disease is properly identified, quantified, characterized and treated at the three levels of healthcare. In primary healthcare, accurate measurement of pain combined with better care may decrease acute painful episodes and consequently minimize tissue damage, thus improving the patient's overall health.

Keywords: Hemoglobinopathies; Anemia, sickle cell; Pain measurement; Primary healthcare; Home visit

\section{Introduction}

Sickle cell disease (SCD) is an umbrella term that encompasses a group of hereditary hemolytic anemia, characterized by the predominance of hemoglobin $\mathrm{S}(\mathrm{Hb} \mathrm{S})^{(1)}$. This is one of the most common genetic diseases in humans ${ }^{(2,3)}$. In Brazil it is a public health problem, which was the reason that it was included in the National Neonatal Screening Program of the Ministry of Health ${ }^{(3,4)}$.

The occurrence of vaso-occlusions, especially of small vessels, represents the pathophysiological event that is the cause of the majority of the signs and symptoms of the disease $^{(5)}$. Pain, the most common symptom in this process, has a direct impact on the quality of life of the patient, family and caregivers ${ }^{(6)}$; its relevance has often been underestimated ${ }^{(7,8)}$. The pathophysiology of pain in SCD is complex, and probably heterogeneous depending on its location ${ }^{(8)}$. There are three types of pain in SCD: recurring acute painful crises, chronic painful syndromes and neuropathic pain ${ }^{(9)}$.

Acute episodic nociceptive-type pain is the primary pain of the disease. It is sharp, intense and evolves rapidly, mainly affecting the osteoarticular system as is well documented in the literature ${ }^{(2,10,11)}$. Chronic pain syndrome (duration longer than three months) and neuropathic pain (nerve injury) are poorly documented ${ }^{(9,11)}$. A clear delineation between the types of pain in SCD is not always possible ${ }^{(10)}$. Recent studies have suggested a reformulation in the evaluation of the characteristics of pain in SCD, proposing a time evolution of the triggering mechanisms $\mathrm{s}^{(9,12,13)}$. It has been reported that nociceptive-type pain is predominantly reported in the first two decades of life. The neuropathic phenomena can be added from the third decade or occasionally earlier in young people who suffer constant and intense episodes of pain, due to extensive exhibition of continuous nociceptive noxic stimuli that lead to central sensitization causing chronic pain with possible neuropathic features ${ }^{(12,13)}$. There is growing evidence that inflammatory stress in the microvascular environment can play an important role in maintaining painful episodes ${ }^{(2,9)}$. Some authors report that these patients live with the pain, however it is not diagnosed nor treated and thus remains a challenge ${ }^{(9,10)}$. Severe and persistent painful crises are poor prognostic and predictive factors for early death ${ }^{(2)}$.

Treatment of SCD, as a whole, presents different hierarchical complexities on a continuum between periods of well-being to the necessity of urgent and emergency therapy, notably in regards to painful crises. The perception of treatment over time has always been considered a problem of tertiary healthcare provided in specialist treatment centers. The secondary and primary healthcare services traditionally do not understand or even ignore this disease ${ }^{(10)}$. 
When patients or family members resort to basic urgent healthcare services or need attention in inpatient units, in particular primary services, patients are often treated by insecure professionals with inadequate training to provide skilled care to patients and caregivers ${ }^{(14)}$.

Analgesic therapy to treat painful crises should be based on the intensity of the pain evaluated using scales, such as the Numeric Pain Scale (NPS) ${ }^{(15)}$ and medications should be administered according to the analgesic ladder of the World Health Organization $(\mathrm{WHO})^{(16,17)}$.

The nurse, as a political agent of social transformation, plays an important role in improving the quality of life of patients with SCD by providing support in pain relief in the primary, secondary and tertiary levels of care. This intervention can be carried out by appropriately receiving the patient and family in the healthcare unit, assisting to evaluate the pain, to apply prescribed medications and to assess the therapeutic response, as well as providing guidance about treatment both to the patient and family members ${ }^{(14)}$.

In view of the high rate and importance of pain in SCD, it is essential that it is properly identified, quantified, characterized and addressed at all three levels of healthcare. The aim of this work was to assess the approach to pain in respect to SCD at the primary healthcare level from the point of view of the registered nurse.

\section{Methods}

This exploratory cross-sectional study was approved by the Research Ethics Committee of the Universidade Federal do Triângulo Mineiro (UFTM; CEP/UFTM \#669 on May 19, 2006). Participant inclusion criteria were to have SCD, age greater than or equal to 18 years and to reside in the city of Uberaba, regardless of ethnical background. All participants gave their written informed consent.

All participants were interviewed in home visits between July 2007 and July 2008. The interviewers were medical and nursing students from UFTM, who belonged to the League to Study and Provide Support for Patients with Pain (LEAD-UFTM), guided and supervised by a nurse. Lists of patients were obtained from the Regional Blood Bank of Uberaba (HRU) and the Regional Association of Thalassemia Patients (PANTS). All patients that resided in the city of Uberaba were visited in their homes.

The research instrument of this study obtained information on general aspects of the underlying disease and aspects related to pain. One-dimensional (NPS) ${ }^{(15)}$ and multidimensional (McGill Pain questionnaire - MPQ) scales were used to assess pain ${ }^{(18)}$. Pain intensity was evaluated over the previous seven days using the NPS. Responses were categorized in four tiers according to the WHO Analgesic Ladder ${ }^{(17)}$ : without pain (0), mild pain (1 to 3 ), moderate pain (4 to 7 ) and intense/severe pain (8 to 10). The MPQ was used to qualify the pain. This questionnaire evaluates the sensory, affective and evaluative dimensions of pain based on the words that the patient chooses to describe painful experiences. The questionnaire is composed of 78 descriptors categorized in four groups (dimensions) and 20 subgroups, ranging from 0 to 78 (the higher the index, the greater the intensity of the pain). It also includes a body diagram so that the patient can indicate the location of the pain ${ }^{(18)}$. Additionally, the number of painful crises per year, response to home treatment and the time before requesting medical assistance were also evaluated.

Data were analyzed using the Statistical Package for Social Sciences (SPSS) program for Windows. Initially a descriptive analysis to characterize the sample and the pain reported by patients was carried out and recorded as percentages and means. The results of this analysis were organized in tables. The associations between the groups of patients with different types of SCD ( $\mathrm{Hb} \mathrm{SS}, \mathrm{Hb} \mathrm{SC}$, sickle $\beta$-thalassemia and others) and pain were assessed with the construction of contingency tables. Subsequently, nonparametric tests of associations (Chi-square, Fisher's and Kruskal-Wallis tests) were applied. A level of 5\% (p-value $<0.05$ ) was set for the rejection of the null hypothesis ${ }^{(19)}$.

\section{Results}

The study population included 47 of the 54 over 18-year-old patients with SCD who resided in Uberaba and were registered in the HRU and PANTS. Seven were not found at the addresses in their medical records. Participants' ages ranged from 18 to 60 years with a mean of 30.1 years $(\mathrm{SD}=10.9$ years). Of these, $78.7 \%$ were black, $17.0 \%$ were mulattos and $4.3 \%$ were Caucasians. There was a predominance of women (59.6\%). All the participants' homes had basic sanitation and $74.5 \%$ of patients resided in the outskirts, that is, the poorer areas of the city. In relation to education, $42.5 \%$ had at least completed high school. As for occupation, $59.6 \%$ did not work or had activities without fixed remuneration. The most common jobs of those who worked were housemaids and handyman. Only $2.1 \%$ of the individuals had wages of more than one minimum wage.

Of the 47 patients, $63.8 \%$ had sickle cell anemia (Hb SS); $78 \%$ had been submitted to blood transfusions at some time during their lives and $12.8 \%$ were taking or had taken hydroxyurea.

Of the total, $95.7 \%$ reported having suffered from pain related to the disease at some time during their lives, with $61.7 \%$ presenting pain within the previous six months, $53.2 \%$ within the previous three months, $29.8 \%$ within the previous week and $14.9 \%$ at the time of the interview. In respect to the location of the pain, $74.5 \%$ of patients had pain in the legs and $57.4 \%$ in the arms. For $46.8 \%$ of the participants, pain occurred in three or more locations at the same time (Figure 1). Pain was more common in the winter $(68.1 \%)$ compared to the other seasons. The duration of painful crises for $25.5 \%$ of the patients was less than a day, for $42.5 \%$ it was between one day and one week, for $19.2 \%$ it was more than one week, $8.5 \%$ did not know its duration and for $4.3 \%$ the pain was daily. When the patient felt pain, the initial treatment included rest $(38.3 \%)$, hydration $(42.6 \%)$ and taking anti-inflammatory drugs and/or painkillers $(57.8 \%)$. Weak opioids were used by $36.2 \%$ of the patients with or without common analgesics; no patient used strong opioids and only $4.3 \%$ used analgesics associated to other medications such as anxiolytic drugs. Few of the participants $(38.3 \%)$ sought medical assistance immediately or within a few hours of feeling pain, while $14.9 \%$ did not seek assistance even with intense pain. Pain considered unconnected to SCD was reported by $19.1 \%$ of the patients with the most common being headaches and epigastralgia. 


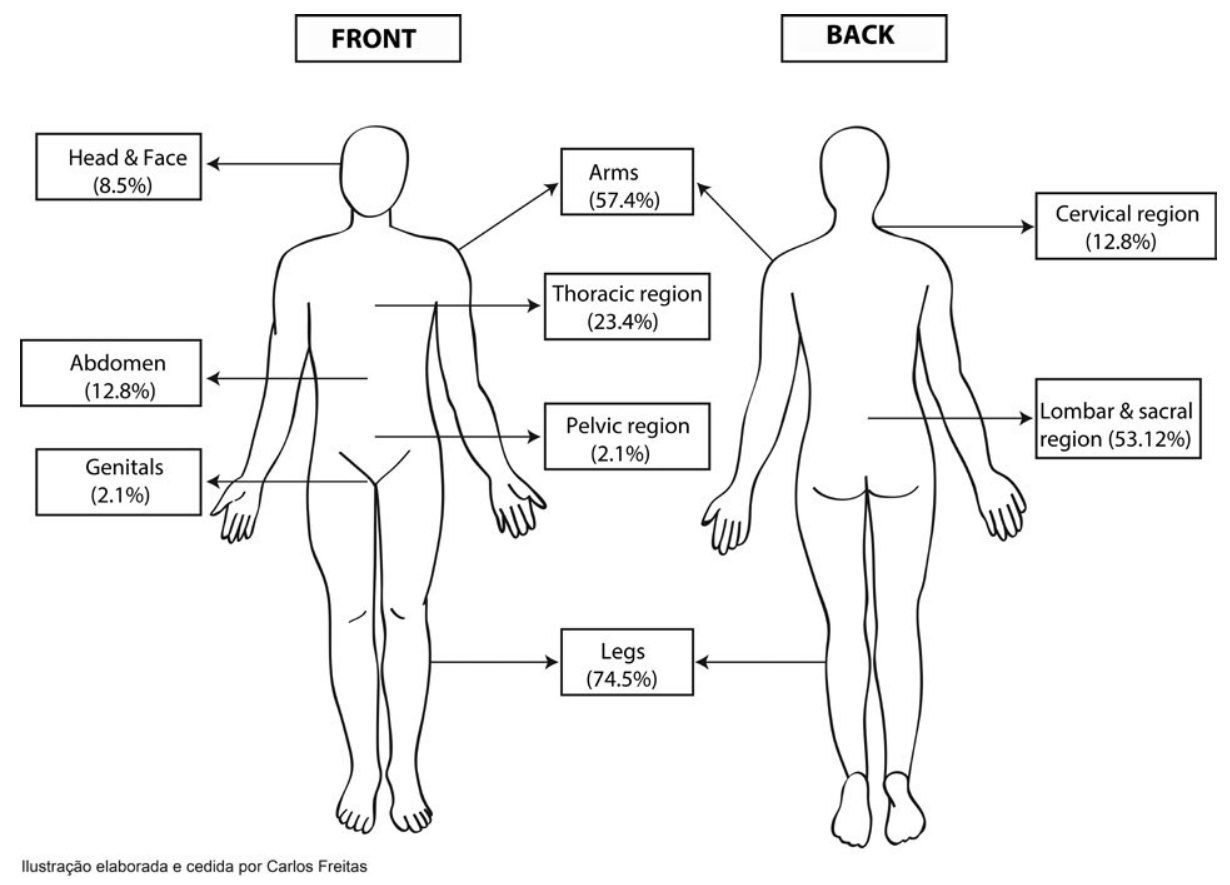

Figure 1 - Diagram to identify region of pain in patients with sickle cell disease

The different clinical forms of hemoglobinopathies were associated with the number of annual crisis; a statistically significant association was observed between sickle cell anemia (Hb SS) and the number of painful crises (Table 1).

Table 1 - Annual quantification of painful crises in patients with sickle cell disease according to the form of hemoglobinopathy ( $\mathrm{Hb} \mathrm{SS}, \mathrm{Hb} \mathrm{SC}$, sickle $\beta$-thalassemia, unknown)

\begin{tabular}{lrccc}
\hline Hemoglobinopathy & $\mathbf{n}$ & $\begin{array}{c}\text { Maximum } \\
\text { crises }\end{array}$ & $\begin{array}{c}\text { Total } \\
\text { crises }\end{array}$ & Mean \\
\hline Hb SS & 30 & 70 & 275 & 9.1 \\
Hb SC & 8 & 8 & 21 & 2.4 \\
Sickle $\beta$-thalassemia & 5 & 24 & 30 & 6.0 \\
Unknown & 4 & 3 & 4 & 1.0 \\
Total & 47 & - & 326 & 7.0 \\
\hline
\end{tabular}

For statistical analysis the forms of sickle cell disease were grouped into $\mathrm{Hb} \mathrm{SS}$ and others (Hb SC, sickle $\beta$-thalassemia and unknown)

Chi-square test; $\mathrm{p}$-value $=0.0015$

Pain intensity was assessed by NPS in the $29.8 \%$ of patients who had had a crisis within the previous week. There was no association between pain and gender ( $p$-value $=0.765$; Fisher's exact test). The mean pain intensity was 5.5 . However, $28.6 \%$ of these patients reported the pain as intense or intolerable, even those who remained at home. Only $27.7 \%$ of patients reported that healthcare professionals had evaluated their pain using the NPS in previous painful crises.

The MPQ was applied in 44 patients who had suffered pain related to SCD. There was great variability of responses. All 20 subgroups of the four domains of the MPQ were mentioned. Of the 78 descriptors, the most cited were: throbbing-type (59.6\%) and twinge-type pain $(53.2 \%)$ - sensory domain; nauseous $(46.8 \%)$
- affective domain; irritating pain (36.0\%) - evaluative domain and irradiating pain (46.8\%) - miscellaneous. The following neuropathic pain descriptors were cited: burning pain $(27.2 \%)$, heat-type pain $(15.9 \%)$, branding pain $(9.0 \%)$ and tingling pain $(6.8 \%)$. Only four of the 78 descriptors (vibrating, such as being hit, itching and tight pain) were not cited. The quantitative index of pain was $35.9 \%$ (Table 2). Descriptors from the sensory domain were the most cited.

Table 2 - Distribution of variability of the number of descriptors chosen by patients and the mean pain index according to the domains of the McGill Pain questionnaire

\begin{tabular}{lcccc}
\hline $\begin{array}{c}\text { Domain } \\
\text { subgroups }\end{array}$ & Variability & $\begin{array}{l}\mathbf{N}^{\circ} \text { of descriptors } \\
\text { chosen }\end{array}$ & $\begin{array}{l}\text { Pain index } \\
\text { (mean) }\end{array}$ \\
\hline Sensorial & 0 & 42 & 39 & 19.0 \\
Affective & 0 & 14 & 14 & 7.3 \\
Evaluative & 0 & 5 & 5 & 3.1 \\
Miscellaneous & 0 & 17 & 16 & 6.5 \\
Total & 0 & 78 & 74 & 35.9 \\
\hline
\end{tabular}

With regard to multidimensional pain assessment, an association of the forms of hemoglobinopathy ( $\mathrm{Hb} \mathrm{SS}, \mathrm{Hb} \mathrm{SC}$, sickle $\beta$-thalassemia) was used to compare the domains of the MPQ. The mean intensity of pain in the sensory domain fluctuated between 16 and 20, in the affective domain between 6 and 7.5, in the evaluative domain between 3 and 4 and in the miscellaneous domain between 4 and 9 . No significant difference was observed between the choice of the type of descriptor (domain), number of descriptors and forms of hemoglobinopathy ( $p$-value $>0.05$ ). 


\section{Discussion}

The painful sensory experience in adults with SCD has not been effectively evaluated as has been suggested by several authors $^{(7,9,10,12,13)}$. Concern that clinical information should include the characteristics of this experience, such as: the location, intensity, frequency and quality of pain are essential elements for the therapeutic planning of these patients ${ }^{(12)}$. Most papers evaluate pain in SCD related to hospital demand however this is only the 'tip of the iceberg' ${ }^{(13)}$. Most crises are treated at home and their prevalence is probably underestimated by healthcare providers, resulting in errors in classification and communication and undertreatment ${ }^{(7)}$. Authors highlight the need for a broader assessment including reported outpatient and home crises as often the patient and family are reluctant to go to hospital even for episodes of badly resolved pain ${ }^{(9,20)}$.

This study set out to document, simultaneously, the location, intensity and the qualification of pain in adults with SCD, through at-home interviews. Reports on this subject are scarce in Brazilian publications. Almost all patients $(95 \%)$ reported having suffered pain related to the disease at some time in their lives. The high frequency of pain related to SCD was also described by another author who found that pain was reported by $100 \%$ of the individuals evaluated $^{(21)}$. Patients, after training, were able to identify acute painful episodes due to sickling, but still reported having pain due to complications related to the disease, such as leg ulcers, aseptic necrosis of the femoral head and daily pain without any sign of sickling. Yet one-third of the patients reported pain unrelated to the disease, including headaches and epigastralgia.

A multicenter study demonstrated that the identification and understanding of the combinations of the location, intensity and quality of pain, may assist in its treatment in $\mathrm{SCD}^{(8)}$. This study reported a mean of 3.3/16 painful sites per patient but this varied considerably both in the same patient and between patients, according to age, emotional state, gender and pain frequency; pain most commonly occurred in the lumbar region and the $\operatorname{legs}^{(8)}$. Similar data were found in the current study, in which half of the patients reported three or more painful places with greater involvement of the lower limbs, followed by upper and lower back.

Bouts of pain due to sickling varied in one year from 0 to 70 with a mean of 7.02 crises/year and with a higher incidence in patients with sickle cell anemia (Hb SS). These data corroborate the literature which states that the Hb SS hemoglobinopathy is the most severe form, evolving with greater intensity and a higher frequency of painful crises ${ }^{(22)}$. About $5 \%$ of the patients in this study had more than ten bouts of severe pain due to sickling in the preceding year and more than half had suffered pain within the previous three months with up to five crises in this period lasting for up to a week. For some the pain was daily.

Intensity was evaluated and compared in respect to gender in the patients that had presented pain in the previous seven days. According to the NPS, the mean intensity was 5.5 and thus considered moderate pain, with approximately 13 patients suffering severe or excruciating pain (between 8 and 10). There was no difference in the pain intensity between male and female patients with the mean pain intensity being similar in both genders; data similar to those found in the literature ${ }^{(23)}$.
In the current study, the initial treatment of pain at home included oral hydration, use of painkillers and sleep, which sometimes resulted in partial improvement of the symptoms. About one third of the patients reported that they sought medical care between one day and one week after the onset of sickling crises. However, about one fifth said they did not seek medical assistance, even with intense pain and treated their painful crises at home without proper guidance. It is believed that this occurs due to the low level of understanding or information about the disease or even to a lack of confidence in these resources even though the city of Uberaba has a structured care program for SCD patients at the secondary healthcare level (outpatient service). Nevertheless, the evaluations of painful crises at home should also be considered by family health programs due to the reluctance of patients to go to hospital even in cases of poorly resolved episodes. To this end, these teams must be properly trained and guided. A recent study has shown that these crises handled at home are often severe and have a high biopsychosocial impact as they are the target of varying unplanned self-medication interventions which are generally ineffective and are not included in most studies, which generally only assess the pain of patients treated in hospital ${ }^{(13)}$.

Moreover, the location and intensity of pain in SCD is of fundamental importance in planning treatment ${ }^{(12,13)}$. These aspects have been documented and compared with pain in cancer patients in an international study ${ }^{(12)}$. The authors found unexpected data: patients with SCD selected verbal descriptors that are associated with or predictive of neuropathic pain found in other diseases, such as cancer. The characteristics of pain in patients with SCD, mixed neuropathic and nociceptive elements and the scores on assessment scales were similar to or even higher than in cancer patients ${ }^{(12)}$.

In the present study qualitative components (sensory, affective and evaluative) of pain in SCD were also evaluated using the $\mathrm{MPQ}^{(18)}$. There was no difference in the choice of descriptors between men and women. In the sensory domain, both men and women chose the descriptors: 'throbbing', 'pang' and 'sharp'. These descriptors are related to mechanical, temporal, spatial and pressure properties of the pain of patients suffering tissue changes during episodes of acute pain ${ }^{(18)}$; in this study these sensations were identified as the main features of the sensory manifestations caused by the vaso-occlusive crises of SCD. The words 'nauseous', 'exhausting' and 'terrifying' were chosen in the affective component. These descriptors show affective dimension behavior with tension, fear and neurovegetative aspects related to acute pain crises $^{(18)}$, aspects that are often observed in SCD. In the evaluative domain, the most commonly used descriptor was 'that irritates' with this being the patients' overall perception of their painful experiences.

Patients with chronic pain, especially oncological pain, tend to use more affective descriptors to report their painful experience $^{(12)}$. In cases of acute pain, there seems to be a preference for sensory descriptors ${ }^{(24)}$. In a study of pain in cancer, it was observed that the mean pain index evaluated by the descriptors of MPQ was 30.8, with the highest score being for the affective domain $(26.4 \%)^{(25)}$. In the current study, a quantitative index for pain of 35.9 was observed with the highest number of responses 
being for the sensory domain (nearly 60\%) inferring that these were the predominant features of acute painful crises in SCD.

Descriptors of neuropathic pain (burning, heat-type, branding and tingling pain) were also observed in this study for about a quarter of the patients. Neuropathic pain descriptors are frequently used in chronic pain, in which there is injury to the nervous system. Due to the large variability in qualitative descriptions of pain, it was observed that affective and evaluative features should be better studied in addition to cognitive aspects. This finding of pain with nociceptive and neuropathic components requires further studies to determine the real presence of these elements in SCD that, according to the authors of a Brazilian study on pain in SCD ${ }^{(2)}$, are rare. However, this description of neuropathic components in SCD has been well documented in some international publications $\mathrm{s}^{(9,11)}$.

The findings of the current study show that sensory and affective qualities with negative emotions reflect the complexity of the painful phenomenon in SCD and that this can significantly influence the quality of life of these patients, mainly in respect to work, professional and social/leisure activities. These facts were stated in an earlier work that described the social aspects of SCD of the same patients as in this study. Most of the patients resided in the outskirts, that is, poorer parts of the city and had poorly paid professional activities or did not have a fixed profession, a condition mainly resulting from the almost constant presence of painful and disabling episodes ${ }^{(26)}$.

It was observed in the current study that the patient with SCD had changes in all the dimensions of the painful process, making it clear that a multidimensional evaluation may assist in the therapeutic planning. A multidisciplinary intervention should be carried out since childhood involving the three levels of healthcare (primary, secondary and tertiary). Thus, preventive measures with monitoring of painful episodes, employment and leisure guidance appropriate for the underlying disease and easy access to healthcare services with fast and efficient treatment of complications, would certainly positively impact on the quality of life and survival of these patients. In this work, the importance of effective measures of health professionals in primary healthcare, through the family health programs and local outpatient clinics is evident.

In addition, SCD deserves more attention from those who program and implement public healthcare policies, especially measures related to the level of primary healthcare, as this disease is a public health problem in Brazil.

\section{Conclusion}

Moderately intense acute pain with key features in the sensory domain of MPQ was highly prevalent in patients with sickling evaluated at home. Descriptors of neuropathic pain were also reported in this study. Opioid analgesics were rarely prescribed. The evaluation instruments used in this study were effective to show the profile of patients with pain due to the sickling process. With these findings, it is clear that the treatment of pain should be based on the pathophysiological mechanisms of the disease and based on the individual patient's evaluation criteria.

\section{References}

1. Agência Nacional de Vigilância Sanitária. Manual de diagnóstico e tratamento de doenças falciformes [Internet]. Brasília: ANVISA; 2002. [cited 2012 Nov 21]. Available from: http://bvsms.saude.gov.br/bvs/ publicacoes/anvisa/diagnostico.pdf

2. Lobo C, Marra VN, Silva RM. Crises dolorosas na doença falciforme. Rev Bras Hematol Hemoter. 2007;29(3):247-58.

3. Ministério da Saúde. Portaria n ${ }^{\circ} 822$, de 06 de junho de 2001. Estabelece a obrigatoriedade de que os hospitais e demais estabelecimentos de atenção à saúde de gestantes, públicos e particulares, procedam a exames visando o diagnóstico e terapêutica de anormalidades no metabolismo do recém-nascido, bem como prestar orientação aos pais [Internet]. Brasília; MS; 2001 [cited 2012 Sep 15]. Available from: http://bvsms.saude.gov br/bvs/saudelegis/gm/2001/prt0822_06_06_2001.html

4. Ministério da Saúde. Manual de Educação em Saúde: auto-cuidado na doença falciforme[Internet]. Brasília (DF): MS; 2008 [cited 2010 Jun 23]. Available from: http://bvsms.saude.gov.br/bvs/publicacoes/manual_ educacao_saude_volume1.pdf

5. Ballas SK. Current issues in sickle cell pain and its management. Hematology Am Soc Hematol Educ Program. 2007;97-105.

6. Howard JO, Thomas VJ, Rawle HM. Pain management and quality of life in sickle cell disease. Expert Rev Pharmacoecon Outcomes Res. 2009;9(4):347-52.

7. Smith WR, Penberthy LT, Bovbjerg VE, McClish DK, Roberts JD, Dahman B, et al. Daily Assessment of Pain in Adults with Sickle Cell Disease. Ann Intern Med. 2008;148(2):94-101. Comment in: Ann Intern Med. 2008;148(2):I36.

8. McClish DK, Smith WR, Dahman B, Levenson JL, Roberts JD, Penberthy LT, et al. Pain site frequency and location in sickle cell disease: The PiSCES project. Pain. 2009;145(1-2):246-51.

9. Ballas SK, Gupta K, Adams-Graves P. Sickle cell pain: a critical reappraisal. Blood. 2012;120(18):3647-56.

10. Naoum PC, Naoum FA. Doença das células falciformes. São Paulo (SP): Sarvier; 2004. 224p.

11. Wilkie DJ, Molokie R, Boyd-Seal D, Suarez ML, Kim YO, Zong S, et al. Patient-reported outcomes: descriptors of nociceptive and neuropathic pain and barriers to effective pain management in adult outpatients with sickle cell disease. J Natl Med Assoc. 2010;102(1):18-27.

12. Smith WR, Scherer M. Sickle-cell pain: advances in epidemiology and etiology. Hematology Am Soc Hematol Educ Program. 2010;2010:409-15.

13. Benjamin L. Pain management in sickle cell disease: palliative care begins at birth? Hematology Am Soc Hematol Educ Program. 2008:466-74.

14. Kikuchi BA. Assistência de enfermagem na doença falciforme nos serviços de atenção básica. Rev Bras Hematol Hemoter. 2007;29(3):331-8.

15. Huskisson EC. Measurement of pain. Lancet. 1974;92(7889):1127-31.

16. Vargas-Shaffer G. Is the WHO analgesic ladder still valid?: Twenty-for years of experience. Can Fam Physician. 2010;56(6):514-7, e202-5.

17. World Health Organization. Cancer pain relief and palliative care. Report of a WHO Expert Committee World Health Organization. Geneva: WHO; 1990.75p. [Technical Report Series, 804].

18. Pimenta CA, Teixeira MJ. Questionário de McGill: proposta de adaptação para a língua portuguesa. Rev Esc Enf USP. 1996;30(3):473-83.

19. Soares JF, Siqueira AL. Introdução à estatística médica. 2nd ed. Belo Horizonte: Coopmed; 2002. 300p.

20. Alvim RC, Viana MB, Rezende PV, Brito AC. Perfil e impacto da dor em 
crianças e adolescentes com doença falciforme [Internet]. Belo Horizonte (MG): Centro de Educação e Apoio para Hemoglobinopatias; 2009 [cited 2011 Mar 16]. Available from: http://www.cehmob.org.br/downloads/ artigo_carrusca.pdf

21. Ivo ML, de Carvalho EC. Assistência de enfermagem a portadores de anemia falciforme, à luz do referencial de Roy. Rev Latinoam Enfermagem. 2003;11(2):192-8.

22. Fuggle P, Shand PA, Gill LJ, Davies SC. Pain, quality of life and coping in sickle cell disease. Arch Dis Child. 1996;75(3):199-203.

23. McClish DK, Levenson LJ, Penberthy LT, Roseff SD, Bovbjerg VE, Roberts JD, et al. Gender differences in pain and healthcare utilization for adult sickle cell patients: The PISCES Project. J Womens Health (Larchmt). 2006;15(2):146-54.

24. Teixeira MJ, Pimenta CA, Grossi AS, Cruz DA. Avaliação da dor: fundamentos teóricos e análise crítica. Rev Med São Paulo. 1997;78(2 pt. 1):85-114.

25. Pimenta CA, Koizumi MS, Teixeira MJ. Dor no doente com câncer: características e controle. Rev Bras Cancerol. 1997;43(1):21-44.

26. Felix AA, Moraes-Souza H, Ribeiro SB. Aspectos epidemiológicos e sociais da doença falciforme. Rev Bras Hematol Hemoter. 2010;32(3):203-8. 